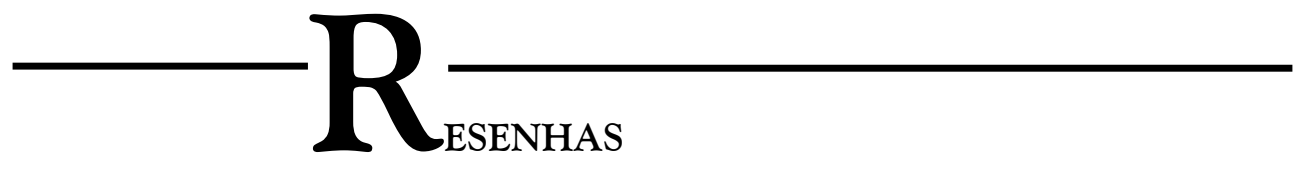

RABELO, Miriam C. M. Enredos, feituras e modos de cuidado: dimensões da vida e da convivência no candomblé. Salvador: EDUFBA, 2014, 296pp.

\title{
SOBRE DINÂMICAS RELACIONAIS, CUIDADOS E SENSIBILIDADES ÉTICAS NO CANDOMBLÉ
}

Lucas Marques

Museu Nacional/UFRJ - Rio de Janeiro

Rio de Janeiro - Brasil

Como fugir das explicações "prontas" sobre o candomblé e narrar as tramas de convivência que são tecidas a partir dos laços entre seres distintos mobilizados no mundo vivido do terreiro? É com base em perguntas deste tipo que Miriam Rabelo empreende sua descrição etnográfica, colocando em diálogo suas posições teóricas e propostas metodológicas num processo de experimentação contínuo e assumido. O livro, vai nos dizer a autora, trata de formas de convivência que são aprendidas e valorizadas nos terreiros de candomblé (:279) - formas estas que envolvem pessoas, lugares, coisas e entidades: orixás, exus, erês e caboclos. Ao optar por essa abordagem, Rabelo nega-se a tratar o candomblé enquanto uma forma cristalizada e pré-moldada, 
lançando um olhar atento sobre as práticas cotidianas, sobre as histórias e trajetórias que engajam mutuamente os seres numa trama relacional específica.

Nesse sentido, o próprio livro é fruto de um (longo) período de convivência. Inicia-se ainda em 1998, quando a autora relata suas primeiras interações com Ritinha e com Mãe Beata - personagem fundamental do livro, Ialorixá da casa na qual Rabelo acabará se envolvendo -, descrevendo suas impressões do local que, anos mais tarde, se tornaria comum à sua vista. Ao longo desse tempo, podemos acompanhar as muitas transformações ocorridas, tanto nos espaços pesquisados quanto na própria autora, que havia iniciado a pesquisa interessada em estudar práticas terapêuticas e, no decorrer dos muitos encontros, envolvimentos e conversas, foi alterando seu foco para os modos de convivência entre os seres e seus entrelaçamentos diversos. À medida que convivia com aquelas pessoas, sua posição no campo ia se modificando: de "apenas pesquisadora", Rabelo foi se inserindo nos círculos de intimidade e convivência que permeiam o terreiro de Mãe Beata, até o ponto de, em 2009, tornar-se filha de santo da casa, quando confirmada equede de Iansã, adquirindo outra posição na dinâmica relacional do terreiro - posição fundamental para a composição mesma do livro.

Assim, Miriam Rabelo não se contenta em narrar somente os atos "públicos" e ritualizados do candomblé, convidando o leitor a conhecer um pouco da prática cotidiana que permeia o terreiro. Indo para além das festas e ritos, a autora traz-nos uma série de práticas que são mobilizadas no cuidado e engajamento íntimo com as entidades, práticas que envolvem toda uma trama de relações que sustenta e dá vida ao terreiro: os preparatórios dos ritos; os caminhos não lineares traçados pelas pessoas; os conflitos que surgem no cotidiano; as atividades "práticas" como limpar, passar, fazer comida; o cuidado cotidiano com os quartos-de-santo; os momentos corriqueiros, que podem tornar-se momentos de aprendizagem; enfim, toda uma trama que se tece no dia a dia da casa, sendo a partir dela que os laços entre pessoas e entidades são conformados.

A narrativa, com base nessa perspectiva, torna-se muito fluida, com um rico esmero etnográfico carregado de experimentação descritiva, entrecortado por mergulhos teóricos profundos e instigantes. Ao dar ênfase ao chamado "mundo vivido do terreiro", Miriam Rabelo vai se inspirar na fenomenologia de Merleau-Ponty e Heidegger - além de outras perspectivas teóricas como a teoria do ator-rede (ANT), o pragmatismo, a etnometodologia e a proposta ecológica de Tim Ingold, dentre outras - para lidar com o fato de que o terreiro de candomblé é um lugar permeado de seres distintos, um mundo de envolvimentos que requer sensibilidades específicas. A fim de dar conta etnograficamente desse mundo, Rabelo vai recorrer, em diversas passagens do livro, à sua própria experiência vivida no terreiro, retratando sua participação enquanto um modo de "estar afetada" naquele ambiente - para usarmos a expressão cunhada por Favret-Saada -, não concedendo à essa participação um estatuto narcisístico ou epistemologicamente privilegiado; antes, trata de levar a sério 
as solicitações das pessoas e do próprio ambiente, perseguindo os encontros, percepções, aprendizagens e enredamentos vividos em sua própria experiência prática.

O livro trata dessas histórias e encontros que ocorreram nesse tempo de convivência. No capítulo que segue a introdução, intitulado "Percursos", Miriam Rabelo narra distintas trajetórias das pessoas com as quais ela conviveu - em especial, os caminhos que elas transitaram antes de chegarem ao terreiro -, compondo com as entidades toda uma rede de relações ricamente diferenciada e múltipla, que envolve experiências com outras religiões, intervalos, hesitações e buscas distintas. Todos esses trânsitos vão tecendo a história particular de cada pessoa. Nesse processo, as entidades atuam de maneira direta e cotidiana, conformando as redes de afinidade e parentesco, de trocas, alianças e disputas envolvendo familiares, vizinhos e outros campos religiosos, extrapolando os espaços do terreiro e atuando no espaço da casa, do bairro ou da rua. Nesse capítulo, portanto, a autora vai mostrar que os percursos da pessoa para chegar ao candomblé, ao contrário do que se diz no "discurso oficial", não decorrem de movimentos lineares; mas, como nos conta a história de Dona Detinha (Ominidê), são traçados segundo uma rede intrincada de caminhos, agenciamentos múltiplos e movimentos variados no tempo e no espaço.

É a partir do capítulo "Histórias e Feituras" que os dois temas fundamentais do livro começam a ganhar destaque, quais sejam: a questão da aprendizagem de habilidades e sensibilidades aos apelos que povoam o espaço do terreiro, e a questão da ética que se gesta como consequência desse aprendizado (:22). Nesse capítulo, Rabelo vai chamar a atenção para o fenômeno da iniciação no candomblé, denominado "feitura do santo", pensando o fazer enquanto um processo de cultivo, que institui uma história que atravessa a pessoa e o próprio lugar. Para isso, conta a história da iniciação de Mãe Beata, num exercício descritivo que multiplica os agenciamentos possíveis, bem como dá atenção ao trabalho minucioso de mobilização de agentes que compõem e decompõem caminhos e relações, conformando enredos possíveis entre a mãe-de-santo, seu orixá (Logun Edé) e os demais seres envolvidos na relação.

Tratando dos pormenores do processo de feitura e aprendizagem no candomblé, a autora vai focar as práticas que antecedem e preparam o recolhimento de uma iaô na casa, que vai desde a confecção das roupas, colares de contas, kelês, contra-eguns, xaorôs e mocãs; perpassa os movimentos intra e extra terreiro; até o aprendizado que se dá para além das danças e cantos e passa por toda uma etiqueta da hierarquia da casa. Esses processos revelam uma noção de aprendizagem específica, em que o conhecimento transita a partir de uma multiplicidade de fragmentos, mas também é retido, apropriado e compartilhado de acordo com a vivência prática. Baseada nessa multiplicidade, a pessoa deve compor uma totalidade - sempre tensionada, em devir - que se torna sua, através de uma "arte da composição" (:284) valorizada enquanto ética do cuidado no candomblé.

O capítulo seguinte, intitulado "Movimento: rodar com santo", vai retomar a questão do aprendizado sob a ótica do mútuo engajamento estabelecido entre pessoa 
e orixá - engajamento este que é vivido principalmente através da experiência de ser tomado pelas entidades, de movimentar-se corporalmente com elas. Retomando a clássica questão da relação entre regra e ação, Rabelo vai propor um novo enquadramento teórico para pensar a possessão, buscando fugir tanto da ideia de que a pessoa teria total controle sobre o estado de possessão - e, portanto, estaria fingindo ou agindo em função de disputas de legitimidade e poder - quanto da ideia, oposta e simétrica, de que a entidade dominaria totalmente as ações perpetradas pelo rodante. Para isso, vai tomar a possessão enquanto uma experiência de alteridade, que engaja um corpo móvel e sensível em uma relação com o orixá, onde ambos experimentam uma "transformação da qual resulta um corpo, um espaço e um tempo - novos, diferentes" (:185). Assim, virar com o santo é sempre um evento relacional, e "o que o filho de santo precisa desenvolver ao longo de sua trajetória no terreiro não é tanto a habilidade da possessão, mas a relação com o santo" (:140).

Ainda tratando dos vínculos cultivados entre as entidades e as pessoas, o capítulo "Assentamento" vai voltar sua atenção para o conjunto de objetos que compõem o assentamento do orixá. Aqui, Miriam Rabelo tenta fugir dos modelos teóricos que lidam com os objetos separando os domínios humanos dos não humanos, os domínios sensíveis dos materiais, buscando então outra perspectiva, mais fenomenológica, que lide com as qualidades sensíveis das coisas (sua expressividade) e os diálogos que estabelecemos com elas. As coisas, vai dizer a autora, são "presenças que nos solicitam, mobilizam nossos corpos e medeiam nossas apreciações e afetos" (:223). Através de uma descrição íntima do ritual do ossé, a limpeza ritual do assentamento - no qual a relação entre corpo e coisa, pessoa e assentamento, é sobretudo uma relação de cuidado -, Rabelo vai falar que o assentamento, no candomblé, é uma confluência de relações, "um lugar em que se encontram um santo, seu filho humano e a mãe de santo que os fez no terreiro" (:228).

Os dois últimos capítulos do livro visam aprofundar a formação de uma conduta ética no candomblé baseada no cuidado. "A comida, o chão, o cuidado" é dedicado ao ritual do bori, ato de alimentar a cabeça da pessoa no candomblé. Descrevendo um bori do qual ela própria participou, Rabelo vai se concentrar nas dinâmicas cotidianas e internas ao ritual (geralmente invisibilizadas nos relatos etnográficos), que situam os participantes num circuito de reciprocidade, gerando pertença e produzindo participação. Essas dinâmicas ocorrem, principalmente, através dos circuitos de comida e de repouso, cada qual integrando uma "multiplicidade de durações" específicas - um voltado para a experiência compartilhada do comer, o outro voltado para a restauração do equilíbrio no dormir e sua submissão ao chão. Esses circuitos colocam-nos frente a uma complexa dinâmica de cuidado, que "não só mobiliza agentes e põe em movimento uma rede extensa de trocas, como também promove transformações" (:262). O cuidado, assim, integra um campo ético específico, inseparável de seu domínio estético, no qual se comprometer com o outro é conformar com ele uma sensibilidade prática: "moldando o corpo, o cuidado produz intimidade e comprometimento com o orixá" (:268). 
Nesse ponto, a autora vai tocar no argumento que baliza todo o livro: que o candomblé requer o cultivo de uma relação, da formação de uma sensibilidade capaz de reconhecer a figura do Outro (a entidade) e mobilizá-la através de uma série de procedimentos que envolvem uma rede de mediação. Logo, a feitura e o cuidado são aspectos de um mesmo processo: "fazer uma pessoa e um santo é sempre também cuidar para que uma relação seja firmada e desenvolvida" (:265).

No capítulo conclusivo do livro, denominado "A multiplicidade e o mundo do terreiro", Miriam Rabelo vai falar que a feitura - pensada enquanto o cultivo de uma relação, que requer aprendizagem e a formação de uma sensibilidade ética que se dá na prática cotidiana - é uma experiência de multiplicidade. Fazer é sempre cultivar uma história, instituir um espaço (o terreiro) que é um espaço de multiplicidade, de múltiplos agenciamentos que escapam ao controle pleno e nos convidam à exploração criativa de um mundo sempre em vias de se fazer. Lidar com essa multiplicidade de agenciamentos e assumi-la positivamente é, portanto, reconhecer que o mundo do candomblé é permeado por outros outros, imprevisíveis, que nos solicitam um engajamento prático e cotidiano, com nós mesmos, com os outros e com o mundo.

É esta, acredito, a grande potencialidade que o livro tem a nos oferecer: seguir os múltiplos engajamentos que as pessoas instituem entre si, com as entidades e com o próprio lugar que habitam. A partir de uma proposta simétrica, que não concede a priori um estatuto privilegiado ao humano, mas segue as linhas de interação acionadas por diferentes seres, Miriam nos convida a embarcar no mundo do candomblé, que é, antes de tudo, um mundo vivido, experienciado corporalmente - e que conforma com este mundo sua própria ética e estética. Trata-se, sem dúvidas, de uma grande contribuição aos chamados "estudos afro-brasileiros" e, mais do que isso, um exemplo à própria antropologia de como realizar conexões produtivas entre a fenomenologia e a etnografia, levando a sério o que as próprias pessoas - e as entidades - dizem, fazem e vivem.

Lucas Marques (paralucas@ymail.com)

Doutorando em Antropologia pelo Programa de Pós-Graduação do Museu Nacional/UFRJ. 